Investigaciones Feministas

ISSN-e: 2171-6080

https://dx.doi.org/10.5209/infe.66368

\title{
Mapas de visibilización de la inseguridad en la ciudad. Estrategia educativa para alumnos/as de Grado de Educación Social
}

\author{
Rafaèle Genet Verney
}

Recibido: Abril 2020 / Revisado: Octubre 2020 / Aceptado: Diciembre 2020

Resumen. Introducción. La ciudad es un espacio comunitario que debería ser legítimo para todos y todas. Sin embargo, la sensación de inseguridad, las agresiones físicas o/y verbales que pueden sufrir las mujeres en la ciudad provocan que no vivan el espacio público de la misma manera que los hombres. Objetivos y metodología. Las políticas urbanas, los estudios sociales tienden a tomar en cuenta esta realidad invisible mediante múltiples acciones que reprimen y evidencian lo que ocurre en la ciudad pero es a través de la educación, y sobre todo la educación no formal, que conseguiremos concienciar a la población sobre lo que realmente sucede en las ciudades. Resultados. Este artículo presenta los resultados de una investigación sobre un proceso docente realizado con alumnos/as de Grado Educación Social de la Facultad de Ciencias de la Educación durante el cual el alumnado reflexionó sobre el papel de la mujer en la ciudad a través de mapas para expresar y visibilizar las distintas sensaciones que les produce el medio urbano.

Palabras clave: Mujer; Ciudad; Educación Social; Educación artística; Mapa.

\section{[en] Maps of visibility of insecurity in the city. Educational strategy for students of Social Education Grade}

\begin{abstract}
Introduction. The city is a community space that should be legitimate for everyone. However, the sensation of insecurity, the physical and/or verbal aggressions that women may suffer in the city causes them not to live in the public space in the same way as men. Objectives and methodology. Urban policies and social studies tend to take into account this invisible reality through multiple actions that repress and evidence what happens in the city, but it is through education, and above all non-formal education, that we will succeed in making the population aware of what really happens in the cities. Results. This article presents the results of a research on a teaching process carried out with students from the Faculty of Education Sciences, during which the students reflected on the role of women in the city through maps to express and make visible the different sensations produced by the urban environment.
\end{abstract}

Keywords: Woman; City; Social Education; Art Education; Map.

Sumario. 1. Introducción. 2. La ciudad un espacio legítimo para todos. 3. La inseguridad, el miedo y las agresiones. 4. Educación social, educación artística, género y ciudad. 5. Mapa de visibilización de la inseguridad en la ciudad. 6. Análisis de los mapas de visibilización. 7. Conclusiones. Referencias Bibliográficas.

Cómo citar: Genet Verney, R. (2021). Mapas de visibilización de la inseguridad en la ciudad. Estrategia educativa para alumnos/as de Grado de Educación Social, en Revista de Investigaciones Feministas 12(1), 215-224.

\section{Introducción}

El espacio público posee una vocación universal, se define como un espacio de ciudadanía en el cual podemos actuar e interactuar todos y todas de manera libre en acorde con las normas de convivencia colectiva. Sin embargo, en la mayoría de nuestras ciudades, la mujer no vive el medio urbano de la misma manera que el hombre. El miedo, la sensación de inseguridad, provoca en las mujeres un comportamiento cohibido que conlleva a que ocupen el espacio urbano de manera muy distinta a los hombres. La ciudad es un ente complejo que es difícil abarcar en todas sus dimensiones sobre todo si se trata indagar sobre sus habitantes, sus sentimientos, emociones o vivencias (Lynch, 2008). En la actualidad muchas investigaciones en ciencias sociales y en urbanismo se centran en el papel de la mujer en la ciudad. ¿Cómo vive el espacio urbano? ¿Existe equidad de

rafagenet@ugr.es

Universidad de Granada, España 
género en la urbe? Todas las mujeres han sufrido algún tipo de agresión o han pasado miedo por la ciudad. Es indudable que existe un problema urbano y social que hay que evidenciar para poder combatirlo y vencerlo. Las mujeres por su actitud en el espacio público intentan esconderlo, minimizarlo, se culpan de ello pero no es solo su responsabilidad, es la de todos. (Beebeejaun, 2017). El miedo por la noche, las agresiones verbales y/o físicas son frecuentes y existen cada vez más maneras de denunciarlas y programas para erradicarlas, pero no se trata tanto de reprimir, sino de transformar y concienciar a la sociedad para que no ocurran.

La educación social es el ámbito de la educación no formal, es por tanto el campo idóneo de acción para llevar a cabo campañas de sensibilización y de visibilización sobre este problema urbano y social. Se puede concienciar a una población mediante políticas y actos sociales enfatizados por los medios de comunicación pero para llegar realmente de manera profunda a la población es necesario tratar este tema desde la educación: enseñar a hablar, a visibilizar, a actuar, en definitiva formar en igualdad de género para transmitir estos valores a la sociedad.

La mayoría de las acciones emprendidas en este campo vienen del campo del urbanismo o de las ciencias sociales como los estudios sobre género. Es necesario unir estos dos campos de conocimiento para generar propuestas educativas que interpelen a la sociedad y creen conciencia. Desde la educación artística se pueden llevar a cabo estrategias didácticas sobre estas temáticas sociales de manera sensible ya que el arte permite una visión del mundo que trasciende lo común de nuestras vivencias y revela la estética humana. El arte es también un instrumento pedagógico válido para revelar problemáticas sociales como la violencia de género y actuar sobre ellas (López F. Cao, 2002). El mapa, utilizado como elemento gráfico y espacial, puede ser una herramienta útil para tratar este tema desde la educación artística. Creando un mapa generamos una única imagen que evidencia rápidamente los problemas y organiza la información a nivel visual y espacial (Agusti, 2005). La construcción de un mapa puede ser también un instrumento metodológico para la enseñanza y la investigación. Es en sí solo un espacio de conocimiento y de divulgación (Genet, 2016).

Este artículo presenta los resultados de una experiencia docente con alumnos y alumnas de Grado de Educación Social de la facultad de Ciencias de la Educación en la cual el mapa se ha convertido en un instrumento de aprendizaje para comprender la cuestión de la mujer en la ciudad. Esta práctica supone también un dispositivo educativo de toma de conciencia que revela a nivel espacial: sentimientos, sensaciones, actos que las mujeres se suelen callar.

\section{La ciudad un espacio legítimo para todos}

Según Lefebvre (1968) la urbe no es sólo un espacio material, sino un nodo producido por las relaciones sociales de sus habitantes. Ellos tienen el poder de transformar su estructura, su funcionamiento. Lefebvre, en su libro "El derecho a la ciudad", distingue tres nociones relacionadas con el espacio: lo percibido, lo concebido y lo vivido. El espacio percibido se refiere a los sentimientos de quienes practican la ciudad. Se podria definir como la memoria de la experiencia urbana. El espacio diseñado o concebido es el espacio dominante de una sociedad creada originalmente por los urbanistas. El espacio vivido, resulta de la relación entre el espacio percibido y el espacio concebido. Es en esta tercera dimensión donde los habitantes de una ciudad pueden intervenir. Por lo tanto, debemos ser conscientes de nuestro espacio percibido para transformar el espacio vivido. Esta conciencia puede ser generada a través de la educación. Esta última permite la aprehensión de la realidad para modificarla y convertirla en un espacio sensible y receptivo para el ser humano.

Si prestamos atención a nuestras acciones cotidianas en la ciudad podemos observar, tanto de manera individual, como de manera colectiva, cómo nos posicionamos respecto al espacio público. Es importante darnos cuenta de cómo pertenecemos a la ciudad, de cómo la vivimos y que derechos tenemos en ella. Certeau en su libro "La invención de lo cotidiano" (1999) distingue los que caminan por la ciudad, es decir los que la practican a diario, de los planificadores y urbanistas. Para él, estos últimos tienen una visión ficticia de la ciudad porque para ellos la ciudad no tiene un sentido personal, una identidad hecha a partir de vivencias.

Para Certeau, caminar, deambular o ir de compras forma parte de una multitud de actividades que incluyen significados que no son obvios para la mirada externa. El andar no se realiza en términos de transporte eficiente, elecciones guiadas por la racionalidad de un mapa, pero como un acto vivencial.

"Los lugares son historias fragmentarias e introvertidas, pasados que a otros no se les permite leer, tiempos acumulados que pueden ser desplegados como historias reservadas, permaneciendo en un estado enigmático, simbolizaciones enquistado en el dolor o placer del cuerpo" (Beebeejaun, 2017).

La ciudad pertenece por tanto más a los que la viven que a los que la programan y planifican. Existe por tanto un derecho a vivir en el espacio público. Este derecho sin embargo no es legítimo para todos. La ciudad no es accesible para la mujer en los mismos términos que para el hombre. Una mujer no puede andar sola por la noche, no puede ir por ciertos barrios, calles, sabe que le puede ocurrir algo y que ya ha pasado. Los planificadores, los poderes sociales y políticos actúan sobre la ciudad para intentar paliar estas desigualdades pero es 
esencial que nosotros mismos actuemos sobre ellas para cambiar, para concienciar, para educar en el respecto y que la ciudad se convierta en un espacio igualitario para todos y todas.

El informe realizado por la Asociación Mundial de las grandes Metrópolis en 2018 indica que existen muchos enfoques de acción para dar respuesta a la violencia contra las mujeres en el espacio público urbano, prevenirla y ponerle fin. La mayoría de las medidas se centran en:

"El uso de legislación para establecer estándares normativos de comportamiento y castigos por transgredir las normas; la articulación de estrategias que se centran en cambiar aspectos de la planificación y el diseño urbano; la detección y respuesta a problemas de seguridad en el transporte público; la utilización de las tecnologías, mediante líneas de atención telefónica, apps móviles y sistemas de mensajes de texto para notificar y crear mapas de zonas de riesgo; y la concepción de programas que varían, desde la sensibilización de la ciudadanía y la educación pública, hasta programas centrados específicamente en roles de género y masculinidad" (McCasland et al., 2018).

Todo este tipo de acciones tienen efectos a corto plazo, y son fundamentales para resolver los problemas inmediatos de la ciudad, pero es necesario profundizar sobre el porqué, para poder tratar el tema y actuar en conjunto como sociedad a largo plazo.

\section{La inseguridad, el miedo y las agresiones}

¿Pero de dónde viene este sentimiento de inseguridad? En primer lugar, es esencial distinguir entre violencia e inseguridad. El primero corresponde a actos mientras que el segundo está relacionado con las consecuencias de estos actos y se vincula con la emoción. La percepción de la vulnerabilidad pocas veces es tomada en cuenta en los planes de seguridad de la ciudad. Sin embargo, afecta muchísimo más nuestras decisiones en cuanto a frecuentar un lugar u otro, pasear por una calle a cierta hora, etc. La ordenación urbanística, el orden y la limpieza, el uso común de los lugares públicos, las distintas formas de apropiársela son elementos que influyen en la sensación de seguridad a nivel colectivo, pero la inseguridad proviene sobre todo de nuestra historia personal, de nuestras vivencias y también de lo que nos han contado y transmitido.

La Encuesta de la European Union Agency for Fundamental Rights, realizada en 2016 indica que: una de cada tres mujeres en la Unión Europea ha sido víctima de violencia física o sexual desde los 15 años; una de cada veinte había sido violada; más de la mitad (55\%) de las mujeres había sufrido acoso sexual. Se suele aconsejar a las mujeres tomar precauciones en el espacio público: andar rápido, no estar aislada, no dar la impresión de tener miedo. Se hace pensar a la mujer que no debería pasear por ciertos lugares ya que puede ser agredida. La vulnerabilidad de las mujeres es un hecho natural desde siempre. Ella misma se inventa estrategias para no estar sola. Según Gardner (1995) la mujer asume que debe tener una vigilancia mental en el espacio público. Como concluyen Hanmer y Saunders (1993) la ciudad es un espacio en el que las mujeres no pueden apropiarse de la misma manera que los hombres. Este derecho legítimo a la urbanidad les es menguado, han perdido autonomía y libertad.

Existen agresiones, acosos y múltiples actos que no se reflejan en las estadísticas porque no son denunciados, no son enunciados por las víctimas. Muchas consideran todavía que puede pasar, que puede ocurrir y sobre todo: que es culpa suya por estar en el lugar inapropiado en el mal momento.

Es necesario tener una concepción amplia del término violencia e integrar comentarios sexistas o tocamientos a este concepto. Para muchos, simples comentarios más o menos agresivos que las mujeres oyen en el espacio público no son violencia en sí. Sin embargo, no se pueden considerar como anodinos, forman parte de la violencia simbólica que tiene también consecuencias. Según Bourdieu (1990), ésta es la que intimida a las mujeres y le lleva a crear estrategias de autoexclusión del espacio urbano.

Según el estudio "Seguridad y espacio público: mapeo de políticas metropolitanas con visión de género" realizado en 2018 por Metrópolis, Asociación mundial de las grandes metrópolis, que cuenta con alrededor de 130 miembros:

\footnotetext{
"Las políticas metropolitanas que abordan la violencia contra mujeres y niñas en el espacio público urbano, se pueden clasificar en: Reactivas: Políticas que dan respuesta a violencia sexual después de que ésta suceda. Implementadas por un $49 \%$ de los miembros.

Preventivas: Políticas que aspiran a prevenir la violencia sexual antes de que ésta se produzca. Implementadas por un $61 \%$ de los miembros

Transformadoras: Políticas que se esfuerzan por ser transformadoras y aspiran a erradicar los arraigados sistemas de opresión que perpetúan la violencia contra mujeres y niñas en la sociedad. Implementadas por un $26 \%$ de los miembros" (McCasland et al., 2018).
}

Reducir la violencia de género en los espacios públicos fomenta que las ciudades sean más inclusivas, accesibles y equitativas para todo el mundo. Muchas mujeres han asumido la responsabilidad de protegerse de la violencia y han desarrollado estrategias para su propia seguridad. Las políticas represivas, las preventivas, 
tienen un efecto a corto plazo, es necesario desarrollar más acciones transformadoras para generalizar una concienciación colectiva. Para obtener resultados a largo plazo y que la mujer tenga derecho al espacio urbano al igual que los hombres se debe fomentar acciones a largo plazo a través de la educación.

\section{Educación social, educación artística, género y ciudad}

Si la educación es el ámbito para desarrollar la capacidad intelectual, es también el lugar de creación de la conciencia moral y afectiva. Permite también crear vínculos entre seres humanos y dar significados a los contextos en que viven (García Roca, 2001). Enseñar es formar a los alumnos y alumnas a que tomen las riendas de su vida, que desarrollen un pensamiento crítico y por lo tanto, se posicionan también respecto cuestiones de género. Para llegar a la totalidad de la población es evidente que se tiene tomar medidas sobre la enseñanza en temas de género en la base de la enseñanza es decir incidir en la formación de formadores.

"El educador o educadora social es un profesional que realiza una acción socioeducativa (prevención e intervención) con personas y/o grupos, desde una línea normalizada o especializada, con objeto de generar cambios para la mejora y transformación social. Promueve la educación a lo largo de toda la vida a través de la participación y el desarrollo del espíritu crítico. Su labor se desarrolla en contextos sociocomunitarios, principalmente en el ámbito no reglado" (Bas-Peña, Pérez-de-Gúzman \& Vargas Vergara, 2014).

Es esencial educar y formar a los futuros educadores en todas las disciplinas a través de proyectos transversales, enseñarles recursos multidisciplinares que les permitan crear estrategias de sensibilización, proyectos de intervención que visibilicen y conciencien sobre la violencia de género en todos sus ámbitos.

Según Hernández (2012, p. 2): "Una de las mayores herramientas que tenemos en la actualidad para combatir la lacra social de la violencia de género es la educación social visualizada desde la perspectiva de la igualdad de género". Sin embargo, según la investigación de Bas Peña y Pérez de Guzmán Puya, la formación sobre género no está muy presente en los estudios de Grado de Educación Social, cuando la mayoría de los encuestados la consideran necesaria para desempeñar su labor profesional.

Bas Peña y Pérez de Guzmán Puya (2014) exponen que:

La intervención educativa ante situaciones de discriminación o violencia contra la mujer reclama competencias, por ello, convendría analizar las competencias requeridas respecto a la prevención, la asistencia, la reinserción, sus conocimientos específicos, como parte de las competencias, para poder actuar. Por ejemplo, podríamos plantear el problema (hechos reales o ficticios) mediante diferentes recursos, analizarlo utilizando las técnicas de dinámica de grupo para promover la participación y la generación del pensamiento, discutirlo con las personas que participan, con otros profesionales, con personas afectadas o con experiencias conocidas o vividas sobre estas cuestiones.

La formación de los educadores sociales debe incorporar, en todas las disciplinas enseñadas, metodologías de intervención social que les permitan llevar a cabo su labor educativo frente a la violencia de género. La educación artística, presente en el currículo de Grado de Educación Social, es una materia que permite abarcar el tema del género desde muchos enfoques pero sobre todo desde su esencia.

El fin último del arte es la creación desde la libertad del ser, y el de la educación, el de desarrollar seres en libertad, capaces de crear y transformar el mundo. Arte y educación son, desde este punto de vista, áreas que tienen fines y objetivos complementarios (López Fdez. Cao, 2003).

La educación artística permite un pensamiento plural y complejo. Trata de reconocer y crear significados sobre lo conocido, lo vivido para transformarlo y hacer evolucionar la sociedad. Es necesario que los alumnos y alumnas sean personas críticas frente a la imagen, que la sepan valorar, que sepan crear imágenes personales mediante conocimientos técnicos pero también simbólicos y estéticos. Nuestro conocimiento sobre la equidad entre géneros proviene de las imágenes asimiladas, de nuestras creencias, de nuestras vivencias. Si pretendemos crear una conciencia crítica en el alumnado debe ser una conciencia creadora, capaz de analizar lo que ve, lo que le rodea, y capaz de interpretarlo y transformarlo. En definitiva, el objetivo primordial es desarrollar el pensamiento creativo y crítico. Es la única manera de que no se reproduzcan y perpetúen las interpretaciones dominantes sobre lo masculino y lo femenino.

Marian López Fdez. Cao es precursora en tratar el tema de la mujer y la igualdad de género en el campo de la educación artística. Su último proyecto "Madrid, ciudad de las mujeres" es:

Una cartografía político-emocional, un proyecto que muestra la presencia, desde distintos puntos de vista, de las mujeres en la ciudad de Madrid, con el ánimo de mostrar también los deseos y expectativas de las mujeres que habitan Madrid, haciendo hincapié en aquellos colectivos que no suelen tener voz: mujeres de diversos extractos sociales y culturales, autóctonas y migrantes, de distintas etnias y procedencias, con problemas de salud mental,... La Ciudad 
de las Mujeres se abre, como un abanico, para mostrar la presencia de las mujeres como motor de expresión, creatividad y actividad de la ciudad, sus elecciones de vida, sus paseos, itinerarios y denuncias (López Fdez. Cao, 2018).

Durante este proyecto se realizaron múltiples talleres que se articulaban alrededor de un mapa interactivo que se construía como lugar de reflexión desde historias de vida personal y colectiva. El proyecto tiene como objetivo mostrar la potencialidad del ser humano para reflexionar sobre su espacio de vida, la habitabilidad de lo urbano, y su capacidad de cambio. Se trataba de pensar la ciudad de Madrid como un espacio vivo, en construcción, un espacio igualitario que fomenta la inclusión y evidencia la capacidad de las mujeres para dar significados y las valide como agentes activas del cambio y transformación de la ciudad.

Parafraseando a Agusti (2005, p. 108), los mapas mentales pueden estructurarse a partir de momentos, sensaciones y encuentros, no necesariamente nacidos de referentes sociales que atribuyen valores a los espacios urbanos. Los mapas mentales no excluyen ningún lugar, espacio o esquina. Todo puede ser insertado en el mapa mental, incluyendo cualquier cosa que de alguna manera genere relaciones entre identidades y experiencias. Es necesario crear mapas mentales del espacio vivido para entender el espacio percibido (Lefebvre, 1991). Por lo tanto, estos mapas no pueden ser formalizados mediante los códigos del espacio político y social. Más bien, deben ser apreciados desde sus aspectos sensibles y estéticos que revelan la experiencia urbana de cada individuo.

Valencia Palacios, por su lado, desde el ámbito académico de la escuela de arquitectura reflexiona sobre la validez de los mapas para generar discursos sobre la ciudad.

"Es posible construir mapas que nos hablen de las muchas ciudades no visibles que conviven en las nuestras, mapas que nos hablen por ejemplo de la vida cotidiana que desarrollamos, de los itinerarios y recorridos, de los eventos urbanos, de aquello que no sólo está estático, de lo que no está lleno, de lo que sucede en simultáneo, de lo hibrido, de lo que está al margen, de lo que no es central, de todo aquello que está soterrado en los rincones físicos y temporales de las urbes a las que pertenecemos" (Valencia, 2009).

Según Valencia, si entendemos como dice Deleuze, la cartografía como "mapa abierto, conectable en todas sus dimensiones, desmontable, alterable, susceptible de recibir constantemente modificaciones" entonces podemos pensar que la cartografía es una manera de pensar el lugar y sus capas superpuestas. Según Cutcher, Rousell y Cutter-Mac Kenzie $(2015,450)$, podemos captar el espacio a través de la estética. La investigación sobre la relación entre lo humano y lo urbano no se centra únicamente en lo humano, sino que se ha convertido en un diálogo colectivo o incluso en un diálogo que va más allá de lo humano.

Apropiarse la ciudad a nivel espacial desde la perspectiva de las emociones, los sentidos es sin duda la manera de llegar a una percepción más completa del espacio urbano. No solo se ve lo individual, sino también lo colectivo. Mediante la superposición de todas las historias de vida contadas, se crea un palimpsesto de conocimiento humano sobre el espacio vivido. Si estos mapas mentales se convierten en instrumentos pedagógicos permiten ayudar a la mujer a percibir la ciudad como un espacio donde poder interferir, actuar y no como un espacio político y urbanístico dado e inmutable.

\section{Mapa de visibilización de la inseguridad en la ciudad}

La estrategia docente que presentamos aquí se realizó en la asignatura de educación artística denominada Construcción Cultural y Colaboración Social con alumnos y alumnas de $3^{\circ}$ curso de Grado Educación Social de la Facultad de Ciencias de la Educación. Formaba parte de un proyecto didáctico sobre el papel de la mujer en la sociedad actual que tuvo lugar al principio de marzo 2018 coincidiendo con el día internacional de la mujer. El proyecto contaba cinco actividades y el aprendizaje de disciplinas artísticas (performance, poema visual, fotografía y cartografía). A nivel pedagógico el proyecto engloba diferentes objetivos: a) concienciar al alumnado sobre la imagen actual de la mujer en la sociedad en general y en particular en la ciudad, a través del análisis audiovisual b) evidenciar los tipos de agresiones verbales, psicológicas o simbólicas existentes en la ciudad contemporánea, c) crear ideas novedosas sobre la imagen mujer mediante la fotografía y el poema visual y d) visibilizar relatos personales en la ciudad a través de la cartografía.

En primer lugar los alumnos/as tuvieron que analizar cuáles eran los estereotipos femeninos recurrentes a través de imágenes seleccionadas de google y de objetos femeninos cotidianos. Este estudio sobre la imagen publicitaria o la estética de los objetos femeninos concienció al alumnado sobre los estereotipos principales del mundo femenino a saber: el rol de la mujer como objeto seductor o el de la ama de casa. Se dieron cuenta así que a pesar de la evolución de los valores de la sociedad, los clichés siguen persistiendo en el tiempo y en las mentalidades. Posteriormente se les propuso crear contra-respuestas a estas imágenes reflejadas por la sociedad a partir de la creación de poema objetos visuales cogiendo de referencia la obra artística del fotógrafo Chema Madoz. Al mezclar objetos contradictorios y simplemente no acorde, encontraron metáforas que hablan de las dualidades de la mujer actual y les ayudó a tomar postura sobre el rol de la mujer en la sociedad.

Tras estos pasos por el mundo de la imagen, se abordó el tema de la ciudad y se empezó a analizar, mediante un debate, cuáles eran las diferentes condiciones de uso del espacio urbano según el género. Las 
palabras recurrentes eran miedo e inseguridad. En ese momento, muchas alumnas ya empezaron a contar delante sus compañeros y compañeras relatos de hechos violentos psicológicamente o/y físicamente. Parecían estar aliviadas de encontrar un espacio para hablar de ello. Tras el debate se les pidió fotografiar los lugares que les inspiraban miedo y los que no, permitiendo así una primera reflexión visual e individual sobre el espacio urbano.

En la sesión siguiente el debate prosigo sobre la legitimidad de la mujer en la ciudad, los distintos tipos de agresiones existentes tanto verbales como físicas así como las distintas emociones que podemos sentir en la ciudad. Se propuso a las alumnas realizar una encuesta visual a partir de un mapa de la ciudad. Se repartió un mapa en papel a cada alumno/a en el cual debían especificar los lugares donde tenían miedo en la ciudad, donde les había ocurrido algún tipo de agresión física o verbal y donde, por lo contrario, se sentían seguro/ as. Aunque la actividad era individual, se les pidió que la realizasen en grupos de cinco o seis. La finalidad implícita era que pudieran hablar de lo que les pasó, para que pudieran compartir con sus compañeros sus experiencias, darse cuenta que todos tienen, que no son responsables, que puede ocurrir en cualquier lugar, incluso en los cuales se sienten seguros/as.

El mapa utilizado era un mapa topográfico de la ciudad similar a los que se utilizan en urbanismo sin ninguna anotación, lo más neutral posible, para considerar todos los lugares de manera equitativa y sin prejuicios. Se les pidió que utilizaran un código de 3 colores para responder de manera unitaria: verde para los lugares seguros, naranja para los lugares inseguros y rojo para los lugares donde hubiera ocurrido algo. El hecho de no poner palabras sobre lo ocurrido o lo sentido les dio cierta libertad a la hora de señalar en el mapa. Tampoco se trataba de inmiscuirse en la vida del alumnado sino que pudieran hablar si lo deseaban. De igual modo, la actividad podía realizarse personalmente o entrevistando a una persona conocida si el alumno o la alumna no quería expresar lo que sentía o había vivido.

A partir de los apuntes sobre el mapa, se creó una base de datos cartográfica que nos enseña los lugares de las agresiones, los lugares que los/as estudiantes consideran seguros o inseguros. Esta nueva cartografía sirve para revelar la realidad de la mujer en la ciudad y concienciar al alumnado sobre lo que sucede realmente en la ciudad, sobre lo que sentimos y percibimos de ella. Los resultados visuales han sido presentados y expuestos a los/as estudiantes de la Facultad de Ciencias de la Educación al año siguiente, el día internacional de la Mujer, para visibilizar esta violencia invisible en la ciudad y debatir sobre qué soluciones podemos apartar desde las ciencias de la educación a un fenómeno tan invisible.

\section{Análisis de los mapas de visibilización}

La encuesta visual recoge los datos de 65 alumnos/as de Grado de Educación Social: 60 alumnas y 5 alumnos. Los alumnos solicitaron entrevistar a compañeras de otros cursos para poder realizar la actividad ya que ellos, en la mayoría de los casos, no habían sufrido agresiones. Consideraron que era más interesante tener la información sobre lo que sentía una mujer que responden ellos mismo a la encuesta visual. Por lo cual los datos corresponden a los de 65 alumnas. Todas indicaron que les había ocurrido algo alguna vez aunque no siempre fuera en la propia ciudad donde estudian.

Para analizar estos datos gráficos y simbólicos se utilizó una metodología de investigación basada en artes, es decir una metodología que utiliza la imagen como fuente de información y de indagación y en la cual la imagen es tratada de manera estética (Eisner y Barone, 1997).

"La representación de los datos mediante métodos visuales es necesaria para enfatizar cualidades estéticas del objeto estudiado, permite encontrar nuevos modos de comunicación y presentación de los resultados. Igualmente la investigación será más sensible a las cualidades sensoriales de las situaciones estudiadas lo cual generará modos innovadores de indagación" (Marín, 2005).

La información recolectada en plano en papel, se trasladó a datos vectoriales mediante el programa de dibujo técnico Autocad que suele ser utilizado por arquitectos y urbanistas para trabajar la ciudad. El programa permite aislar la información deseada para solo enseñar parte de los resultados o enseñarlos en su globalidad. Según Jiménez (2017), los programas informáticos de dibujo técnico pueden convertirse, en una investigación basada en arte, en un instrumento metodológico de investigación y creación. Por otro lado permiten tener una representación espacial a distinta escala. Podemos ver la ciudad en su totalidad y a la vez apreciar todos sus detalles. En definitiva, permite combinar un análisis cuantitativo y espacial con una indagación cualitativa y estética. 


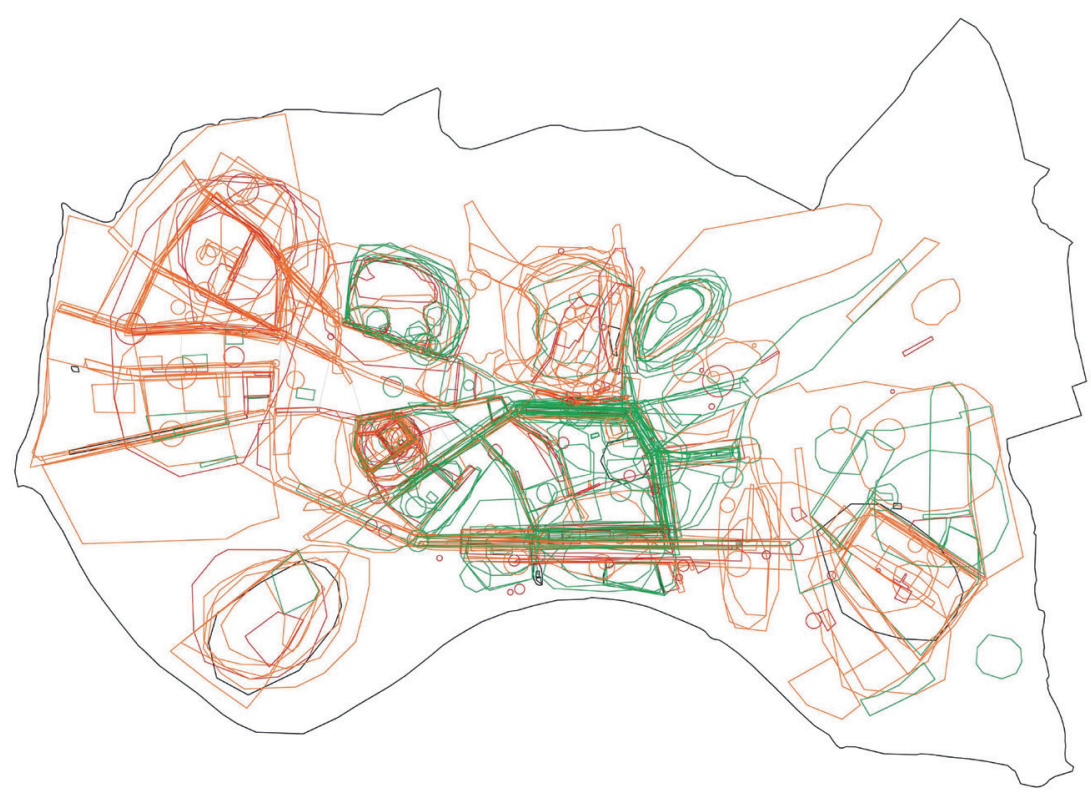

Figura 1. Rafaèle Genet (2019) Croquis de los espacios seguros, inseguros y lugares de agresiones.

La figura 1 corresponde a un primer croquis de los datos recopilados durante la encuesta visual, son contornos de espacios que representan actos, sensaciones, memorias de las estudiantes en la ciudad.

La figura 2, desglosa los datos en tres mapas: a la izquierda están representados los lugares seguros para las alumnas, en el centro los lugares en los cuales sienten inseguridad y a la derecha los lugares donde les ocurrió algo. Cada mapa se ha tratado utilizando la técnica de la media visual. Según Marín y Roldán (2014):

"La media aritmética es la suma de las calificaciones o de los valores de una variable, dividida por el número de calificaciones o valores. La media aritmética es una de las principales medidas de tendencia central (Haber \& Runyon, 1973: 74 y ss.). Para obtener una Media Visual se superponen, a modo de capas transparentes, todas las imágenes visuales disponibles sobre un mismo motivo. En la imagen final aparecerán con mayor opacidad y saturación las zonas en las que las imágenes coincidían, y aparecerán de forma más tenue o velada aquellas zonas o elementos en los que cada fotografía difiere de las otras".

En nuestro caso, se efectuó el mismo proceso de superposición de datos a los cuales se les ha dado un cierto porcentaje de transparencia. Se revelan así con un color más intenso los lugares donde coinciden los datos de las alumnas. Este instrumento metodológico permite colectar la totalidad de los datos conservando su individualidad y presentándose de manera colectiva a la vez. El interés reside en que se destacan las singularidades y se aprecian las similitudes de los datos. En definitiva permite una visión estética de los datos conservando los datos cuantitativos.

De la observación de los tres mapas resultantes podemos sacar conclusiones formales y geográficas de los datos representados y a su vez se puede emitir hipótesis sobre sus orígenes.

En el mapa de los lugares seguros observamos zonas son amplias y circulares, sus contornos son nítidos, parece fácil de identificarlas. Encontramos representados el centro de la ciudad, el campus universitario, algunas zonas residenciales, los parques urbanos más concurridos. Son los lugares más frecuentados de la ciudad por el alumnado y la población en general, son por tanto los más poblados y los más cuidados, los que inspiran mayor confianza.

En el mapa de los lugares inseguros constatamos que estos se despliegan por toda la ciudad. Son zonas amplias que representan barrios enteros o espacios lineales que podrían reflejar trayectos en transportes comunitarios. Todos tienen contornos indefinidos, como si fuera difícil definir hasta dónde acaban. Constatamos que siguen existiendo prejuicios urbanos. Los barrios de reputación inseguros, es decir los barrios desfavorecidos de la ciudad, son en la mayoría de los casos indicados en este mapa aunque la alumna no haya ido nunca. Este mapa por la cantidad de información que contiene, podría simbolizar el miedo invisible que existe en la ciudad. Si lo comparamos con el mapa de los espacios seguros se evidencia que existe o se siente más inseguridad que seguridad en la urbe.

En el mapa de los lugares de agresiones y/o actos violentos verbales o físicos encontramos mucho más zonas pequeñas, espacios más precisos. Estas zonas cuentan historias reales, algo ocurrió en un lugar, en un momento aunque haya desaparecido y no quede rastro de lo sucedido. Gracias a este mapa un sufrimiento, una injusticia, se hace visible. Se ve lo que en muchos casos nunca se ha contado. Sin embargo, tampoco se devela la intimidad de la persona que lo sufrió. 

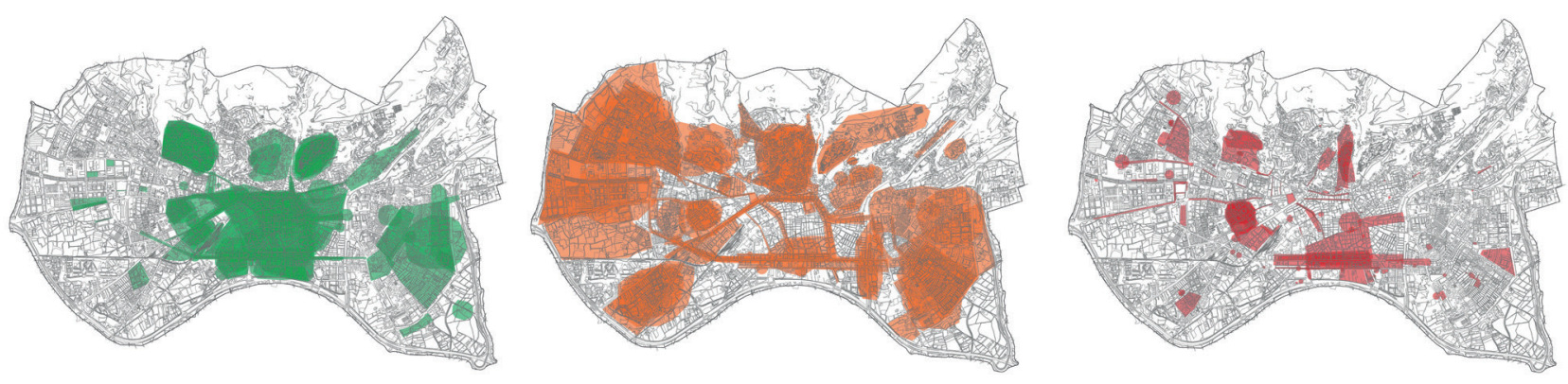

Figura 2. Rafaèle Genet. (2019) Tres mapas de la ciudad: Lugares seguros, lugares inseguros, lugares de agresiones.

En la figura 3 observamos que si simultaneamos y superponemos las distintas zonas pueden coincidir. Un mismo lugar, de día o de noche, con o sin personas puede transformarse y la sensación que procura puede ser completamente distinta. La ciudad no cuenta con un solo color, y en muchos lugares está formada por una mezcla de sensaciones y vivencias. La ciudad nunca ha sido un ente estático, debe seguir siendo un lugar vivo para poder seguir evolucionando hacia un espacio más equitativo para todos.

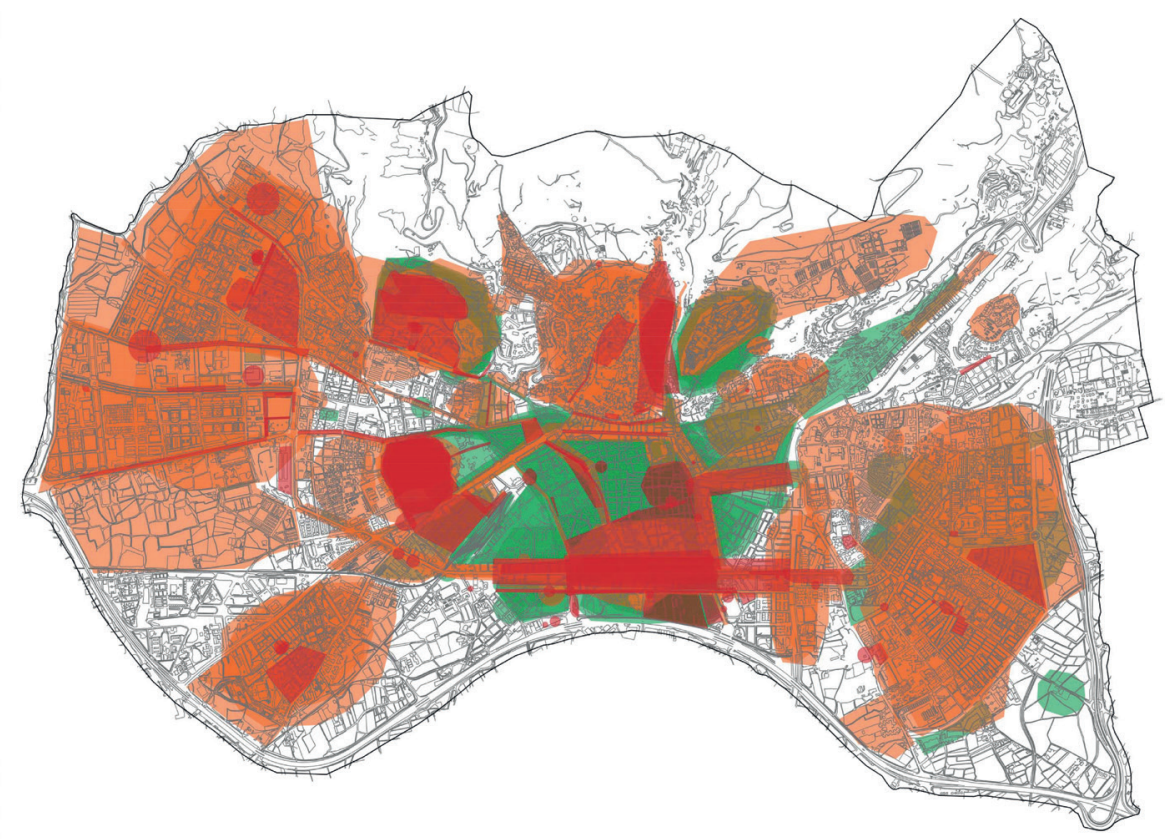

Figura 3. Rafaèle Genet (2019). Mapa de los espacios seguros, inseguros y lugares de agresiones.

\section{Conclusiones}

La ciudad debería ser un espacio igualitario para todos pero no lo es, la mujer está condicionada por una memoria personal y colectiva que le obliga a actuar con cuidado en el espacio público y le obliga a estar a la defensiva. Es necesario generar sentimientos de pertenencia a los espacios urbanos creando identificaciones y representaciones inclusivas y no discriminatorias para las mujeres (Fernández, 2012). Según Ortiz (2014), las ciudades contemporáneas aún tienen entre sus grandes retos el problema de cómo afecta la violencia al derecho a la ciudad de las mujeres. Aunque existen cada vez más acciones en este sentido, todavía no son suficientes las políticas urbanas, de seguridad y de prevención de la violencia. La desigualdad de género en la ciudad sigue siendo poco visible y sigue habiendo muchas agresiones calladas. Además del desarrollo de políticas urbanas es necesario concienciar a la población sobre este problema urbano y social que sigue generando ciudades segregadas en términos de género.

La educación social es el lugar predilecto para tratar este tema por ser el espacio de la enseñanza no formal y el lugar del aprendizaje de la reflexión crítica. Sin embargo, la formación en igualdad de género sigue siendo poco presente en la formación del educador (Bas-Peña y Pérez-de-Gúzman, 2016). Desde su enfoque educativo, la Didáctica de la Expresión Plástica permite relevar a través de lo sensible y de lo estético, lo que sentimos a nivel social. Es por tanto el ámbito idóneo para tratar el tema de la mujer. La interpretación artística 
permite crear una imagen a partir de lo vivido que además evidencia lo sentido. Un mapa además de ser una representación gráfica propone una representación espacial que permite abarcar más fácilmente problemáticas como la ciudad en su totalidad.

A nivel docente, este proyecto intentó revelar miedos urbanos, concienciar sobre las vivencias de la mujer en la ciudad y hablar de sus derechos en su vida cotidiana en el espacio urbano. Es mediante pequeñas pinceladas educativas sobre este tema que, poco a poco, se ira forjando una conciencia colectiva que genera cambios sociales. Como investigación, constatamos que los mapas son válidos a nivel educativo para tratar estos temas invisibles y que las metodologías de investigación basada en artes permiten este tipo de hallazgos visuales que otra indagación cuantitativa no permitiría evidenciar. Su impacto visual es mayor y permite expresar datos de manera más sensible. Igualmente, al tratarse de una imagen, no se obliga a poner palabras sobre los hechos pero sí permite al alumnado expresarse sobre lo visual.

Tanto a nivel educativo como a nivel investigador, como lo comenta Lopez F. Cao en el proyecto "Madrid, ciudad de mujeres", se trata de aportar ideas educativas innovadoras sobre la ciudad y sobre el género para generar cambio. Si consideramos la ciudad como un ente dinámico en el cual los ciudadanos pueden llevar a cabo su transformación, influyendo en las políticas urbanas y sobre todo en los valores de la sociedad, conseguiremos que la ciudad vuelva a ser un lugar habitable y legítimo para todos y todas.

\section{Referencias Bibliográficas}

Agusti, Andreina (2005). Mental maps and city. Fermentum Revista Venezolana de Sociología y Antropología, 15(42), $104-113$.

Barone, Tom \& Eisner, Elliot. W. (1997). Arts-based educational research, en R. Jaeger (ed.), Complimentary Methods of Educational Research, New York: Macmillan Publishing, pp. 95-109.

Bas Peña, Encarnación y Pérez de Guzmán, Vitoria (2016). La formación y la intervención de los educadores/as sociales en cuestiones de género. Educació Social. Revista d'Intervenció Socioeducativa, 63, 95-112.

Bas-Peña, Encarnación; Pérez-de-Guzmán, Victoria y Vargas-Vergara, Montserrat (2014). Educación y género. Formación de los educadores y educadoras sociales. Pedagogía Social. Revista Interuniversitaria, 23, 95-119. DOI: 10.7179/ PSRI_2014.23.05

Beebeejaun, Yasminah (2017). Gender, urban space, and the right to everyday life. Journal of Urban Affairs, 39, $323-334$. DOI: $10.1080 / 07352166.2016 .1255526$

Bourdieu, Pierre (1990). La domination masculine. Actes de la Recherche en Sciences sociales, 84, 2-31. DOI : https://doi. org/10.3406/arss.1990.2947

Cutcher, Alexandra; Rousell, David y Cutter-Mac Kenzie, Amy (2015). Findings, windings and entwinings: Cartographies of collaborative walking and encounter. International Journal of Education through Art, 11(3), 449-458. DOI: http://dx.doi. org/10.1386/eta.11.3.449_1

De Certeau, Michel (1999). La invención de lo cotidiano. México: Universidad Iberoamericana, Biblioteca Francisco Xavier Clavigeuro. Disponible en: https://circulosemiotico.files.wordpress.com/2012/10/de-certeau-michel-la-invencion-de-locotidiano-1-artes-de-hacer.pdf

Deleuze, Gilles y Guattari, Félix (1997). Mil mesetas: capitalismo y esquizofrenia, vol 2. Valencia: Editorial Pre-textos. Disponible en:

http://edwardium.com/wp-content/uploads/2016/05/151653352-Mil-Mesetas-Capitalismo-y-Esquizofrenia-Deleuze-yGuattari.pdf

European Union Agency for Fundamental Rights (FRA) (2016). Zero tolerance of violence against women. Disponible en: https://ec.europa.eu/transparency/regdoc/rep/3/2013/EN/C-2013-7924-F1-EN-MAIN-PART-1.PDF

Fernández Pérez, Zaida (2012). Mapa de las huellas de las mujeres y del feminismo. En Gutiérrez Valdivia, Blanca y Ciocoletto Adriana (2012). Estudios urbanos, género y feminismo. Teoría y experiencias. Barcelona: Col·lectiu Punt 6 . Disponible en: https://punt6.files.wordpress.com/2011/03/estudiosurbanosgenerofeminismo.pdf

García Roca, Joaquín (2001). La navegación y la fisonomía del naufragio. El aspecto moral de las profesiones sociales. En Kisnerman, N. (Eds.), Ética ¿un discurso o una práctica social? Buenos Aires: Paidós.

Gardner, Carol (1995). Passing by: Gender and public harassment. Berkeley: University of California Press. Disponible en: https:/www.ocac.cl/wp-content/uploads/2015/01/Carol-Brooks-Gardner-Passing-by-Gender-and-public-harassment.pdf

Genet Verney, Rafaèle (2016). Ciudad y educación artística en la formación inicial del profesorado: Una investigación educativa basada en las artes visuales. Tesis doctoral. Granada: Universidad de Granada. Disponible en: https://digibug. ugr.es/handle/10481/44551

Hanmer, Jalna y Sheila Saunders (1993). Women, violence and crime prevention: a West Yorkshire study. London: Avebury. [Fecha de Consulta 21 de Octubre de 2019]. Disponible en: http://scholarworks.wmich.edu/cgi/viewcontent. cgi?article $=2207 \&$ context $=$ jssw

Hernández, Carmelo (2012). Violencia de género: Una cuestión de Educación Social. RES. Revista de Educación Social, 14, 1-3. Disponible en: http://www.eduso.net/res/pdf/14/viol_res_14.pdf

Jiménez Montano, Mayra (2017). La fotografia como instrumento de investigación y aprendizaje del taller de proyectos arquitectónicos en el primer año de formación de arquitectos: El uso de métodos artísticos para la definición del problema de diseño en el paisaje urbano de San Juan de Puerto Rico. Tesis doctoral. Granada: Universidad de Granada. [Fecha de Consulta 21 de Octubre de 2019]. Disponible en: https://digibug.ugr.es/handle/10481/47788 
Lefebvre, Henri (1991). The production of space. Oxford: Blackwell. Disponible en: https://monoskop.org/images/7/75/ Lefebvre_Henri_The_Production_of_Space.pdf

López F. Cao, Marian (2002). La educación artística y la equidad de géneros: un asunto pendiente. Arte, Individuo y Sociedad, Anejo 1, 145-171. Disponible en: https://core.ac.uk/download/pdf/38827759.pdf

López F. Cao, Marian. (2003). Educación, creación y género. Educación Artística. Revista de Investigación, Número 1. [Fecha de Consulta 21 de Octubre de 2019]. Disponible en: http://redined.mecd.gob.es/xmlui/bitstream/handle/11162/110226/2003 EARI_01184_LopezFdez.pdf?sequence=1

López F. Cao, Marian (Coord.) (2018). DIVERCITY Diving into Diversity in Museums ans in the City (2014-1-ES01KA204-004799).IO5: Itinerarios feministas por la ciudad, Madrid, ciudad de las mujeres, Una cartografía político/ emocional. Disponible en: https://www.ucm.es/divercity/Productos\%20DIVERCITY

Lynch, Kevin (2008). La Imagen de la Ciudad. Barcelona: Gustavo Gili, S.L. Disponible en: https://taller1smcr.files.wordpress. com/2015/06/kevin-lynch-la-imagen-de-la-ciudad.pdf

Madoz, Chema (2018). Ars combinatoria. Madrid: La Fábrica Editorial.

Marín Viadel, Ricardo (2005). La Investigación Educativa basada en las Artes Visuales o ArteInvestigación Educativa. En Marín Viadel, Ricardo (Ed.), Investigación en educación artística, pp. 223-274. Granada: Universidad de Granada.

Marín Viadel, Ricardo y Roldán, Joaquín (2014). 4 instrumentos cuantitativos y 3 instrumentos cualitativos en Marín Viadel, R., Roldán, J. y Pérez Martín, F. (Eds.), Estrategias, técnicas e instrumentos en Investigación basada en Artes e Investigación Artistica [Strategies, techniques and instruments in Arts based Research and Artistic Research]. Granada: Universidad de Granada. Disponible en https://digibug.ugr.es/handle/10481/34213

McCasland, Hannah; Travers, Kathryn; Llorente Sánchez, Silvia y Brum, Lia (2018). Seguridad y espacio público: mapeo de políticas metropolitanas con visión de género. Metrópolis, asociación mundial de las grandes metrópolis Mujeres y Ciudades Internacional (WICI). Disponible en: https://www.metropolis.org/sites/default/files/resources/Seguridad espacio_p\%C3\%BAblico_Mapeo_genero.pdf

Ortiz Escalante, Sara (2014). En Carmen Cortés Zaborras (coord.) Jornadas Urbanismo y Género. Ciudades en Construcción, pp. 48-67. Perséfone. Ediciones electrónicas de la AEHM/UMA. Disponible en: https://punt6.files.wordpress.com/2014/07/ espaciopublicogc3a9neroeinseguridad_ortiz.pdf

Valencia Palacios, Marco A. (2009). Cartografías urbanas. Imaginarios, huellas, mapas, Revista electrónica DU\&P. Diseño Urbano y Paisaje, 5, 116. 